\title{
Early detection of gastric cancer using global, genome-wide and IRF4, ELMO1, CLIP4 and MSC DNA methylation in endoscopic biopsies
}

\author{
Francesca Pirini ${ }^{1, *}$, Sassan Noazin ${ }^{2, *}$, Martha H. Jahuira-Arias ${ }^{3,4, *}$, Sebastian \\ Rodriguez-Torres $^{3}$, Leah Friess ${ }^{3}$, Christina Michailidi ${ }^{3}$, Jaime Cok $^{5}$, Juan Combe ${ }^{6}$, \\ Gloria Vargas 7 , William Prado ${ }^{8}$, Ethan Soudry ${ }^{3}$, Jimena Pérez ${ }^{3}$, Tikki Yudin ${ }^{3}$, Andrea \\ Mancinelli $^{3}$, Helen Unger ${ }^{3}$, Carmen Ili-Gangas ${ }^{9,10}$, Priscilla Brebi-Mieville ${ }^{9,10}$, \\ Douglas E. Berg ${ }^{11,12}$, Masamichi Hayashi, ${ }^{3,13}$, David Sidransky3 , Robert H. Gilman ${ }^{2,4}$, \\ Rafael Guerrero-Preston ${ }^{3,14}$ \\ ${ }^{1}$ Biosciences Laboratory, Istituto Scientifico Romagnolo per lo Studio e la Cura dei Tumori (IRST) IRCCS, Meldola, Italy \\ ${ }^{2}$ The Johns Hopkins University, Bloomberg School of Public Health, Department of International Health, Baltimore, MD, USA \\ ${ }^{3}$ The Johns Hopkins University, School of Medicine, Otolaryngology Department, Head and Neck Cancer Research Division, \\ Baltimore, MD, USA \\ ${ }^{4}$ Universidad Peruana Cayetano Heredia, Lima, Perú \\ ${ }^{5}$ Hospital Nacional Cayetano Heredia, Pathology Department, Lima, Perú \\ ${ }^{6}$ Instituto Nacional de Enfermedades Neoplásicas, Gastroenterology Department, Lima, Perú \\ ${ }^{7}$ Hospital Nacional Arzobispo Loayza, Gastroenterology Department, Lima, Perú \\ ${ }^{8}$ Hospital Nacional Dos de Mayo, Gastroenterology Department, Lima, Perú \\ ${ }^{9}$ Laboratory of Molecular Pathology, Department of Pathological Anatomy, School of Medicine, Universidad de La Frontera, \\ Temuco, Chile \\ ${ }^{10}$ Center of Excellence in Translational Medicine - Scientific and Technological Bioresource Nucleus (CEMT-BIOREN), \\ Universidad de La Frontera, Temuco, Chile \\ ${ }^{11}$ Washington University Medical School, Department of Molecular Microbiology, St Louis, MO, USA \\ ${ }^{12}$ University of California San Diego, Department of Medicine, La Jolla, CA, USA \\ ${ }^{13}$ Department of Gastroenterological Surgery, Nagoya University Graduate School of Medicine, Nagoya, Japan \\ ${ }^{14}$ University of Puerto Rico School of Medicine, Department of Obstetrics and Gynecology, San Juan, Puerto Rico \\ *These authors equally contributed to this work \\ Correspondence to: Rafael Guerrero-Preston, email: rafael.guerrero@upr.edu \\ Robert H. Gilman, email: rgilman1@jhmi.edu
}

Keywords: translational epigenomics, global DNA methylation index, epigenome-wide DNA methylation analysis, IRF4, ELMO1 Received: January 09, $2017 \quad$ Accepted: February 24, $2017 \quad$ Published: March 16, 2017

Copyright: Francesca Pirini et al. This is an open-access article distributed under the terms of the Creative Commons Attribution License 3.0 (CC BY 3.0), which permits unrestricted use, distribution, and reproduction in any medium, provided the original author and source are credited.

\section{ABSTRACT}

Clinically useful molecular tools to triage gastric cancer patients are not currently available. We aimed to develop a molecular tool to predict gastric cancer risk in endoscopy-driven biopsies obtained from high-risk gastric cancer clinics in low resource settings.

We discovered and validated a DNA methylation biomarker panel in endoscopic samples obtained from 362 patients seen between 2004 and 2009 in three high-risk gastric cancer clinics in Lima, Perú, and validated it in 306 samples from the Cancer Genome Atlas project ("TCGA"). Global, epigenome wide and gene-specific DNA methylation analyses were used in a Phase I Biomarker Development Trial to identify a continuous biomarker panel that combines a Global DNA Methylation Index (GDMI) and promoter DNA methylation levels of IRF4, ELMO1, CLIP4 and MSC.

We observed an inverse association between the GDMI and histological 
progression to gastric cancer, when comparing gastritis patients without metaplasia $($ mean $=5.74,95 \%$ CI, $4.97-6.50)$, gastritis patients with metaplasia (mean $=4.81,95 \%$ CI, 3.77-5.84), and gastric cancer cases (mean $=3.38,95 \% \mathrm{CI}, 2.82-3.94$ ), respectively $(p<0.0001)$. Promoter methylation of IRF4 ( $p<0.0001)$, ELMO1 $(p<0.0001)$, CLIP4 $(p<0.0001)$, and MSC $(p<0.0001)$, is also associated with increasing severity from gastritis with no metaplasia to gastritis with metaplasia and gastric cancer. Our findings suggest that IRF4, ELMO1, CLIP4 and MSC promoter methylation coupled with a GDMI >4 are useful molecular tools for gastric cancer risk stratification in endoscopic biopsies.

\section{BACKGROUND}

Gastric cancer (GC) is the fifth most common cancer in both sexes and the third cause of cancer-related death around the world [1]. Chronic infection of the stomach by the bacterium Helicobacter pylori leading to chronic inflammation is a major attributable risk factor [2], although less than $2 \%$ of $H$. pylori carriers develop gastric cancer [3]. The prognosis of GC is closely related to the stage of disease at the time of diagnosis $[4,5]$. The most widely accepted histopathology-based progression model for the development of intestinal-type gastric adenocarcinoma consists of a transition from superficial gastritis to metaplasia to dysplasia and finally, gastric adenocarcinoma $[6,7]$. When detected at an early stage, $\mathrm{GC}$ is often curable and the five year survival rate is greater than $90 \%$, whereas the prognosis for advanced GC is still poor [8]. Early GC is defined as cancer confined to the mucosa or submucosa regardless of the presence of lymph node metastasis [9], but due to the non specific symptomatology and to the difficulty in distinguishing early GC from benign peptic ulcer or gastritis in the ambulatory setting, less than $20 \%$ of GCs are diagnosed at an early stage worldwide [10].

Endoscopy is widely used for the early diagnosis of gastric cancer because of the high accuracy [11], but an accurate reading depends on the endoscopist's observation skills. Apart from conventional endoscopy, magnifying endoscopy combined with narrow-band imaging (NBI) has been recently introduced in the diagnosis of early GC $[4,12]$ improving the specificity, the sensitivity and the accuracy of the diagnosis [13, 14]. However, missed diagnosis of GC on endoscopy is a common occurrence, with false-negative rates ranging among $5-19 \%[4,15,16]$. Consequently, in addition to technical improvements, the identification of novel biomarkers for early diagnosis is urgently needed.

Promoter hypermethylation of several tumor suppressor genes has been correlated with gastric cancer susceptibility [17]. The literature reports many genes significantly hypermethylated in cancer tissue compared with normal tissue of GC subjects [18-20], but relatively few studies have reported DNA methylation markers for early detection [21-24]. Furthermore, quantification of global 5-methylcytosine content [25] and evaluation of long interspersed nuclear elements (LINEs) by Lee [26] and others have emphasized the importance of global DNA hypomethylation in GCs, although little is known about its role in GC.

H. pylori infection has been correlated with the progressive accumulation of epigenetic alterations in gastric mucosa [17]. Promoter hypermethylation in specific tumor suppressor genes has been associated with $H$. pylori infection in the multistep carcinogenetic process by several groups $[27,28]$. Global DNA hypomethylation also increases throughout the process that leads to the deterioration of normal gastric mucosa to invasive cancer [29-31].

In the present study we used global, genome wide and gene-specific DNA methylation analyses to perform a Phase I Biomarker Development study [32] in order to examine whether gene specific promoter methylation biomarkers, together with a global DNA methylation index (GDMI), could distinguish gastric cancer cases from controls in endoscopic biopsies.

\section{RESULTS}

\section{Participant characteristics}

A total of 376 patients from Peru, mean age $61.2 \pm 14.9$ years and age range $18-88$ years, met the eligibility criteria and were included in our study (Supplementary Tables 1-2). Patients came to the clinic in Peru with the following symptoms: heartburn (81.8\%), belching $(76.4 \%)$, distension (74.2\%), abdominal pain $(51.1 \%)$, nausea $(39.6 \%)$, and acid regurgitation $(26.3 \%)$. There are no significant differences between age and sex in our randomly created Discovery and Validation patient groups: Discovery (Global DNA methylation $n=80$; Gene-specific DNA methylation $n$ $=116$ ) and Validation (Global and Gene-specific DNA methylation $n=180$ ) (Supplementary Figure 1A). We performed epigenome-wide DNA methylation analysis of 30 patients selected from the Discovery cohort and Validated the epigenome-wide DNA methylation results from Peru using data from 316 participants in the Cancer Genome Atlas project (Supplementary Figure 1B).

\section{Biomarker development workflow}

Global DNA methylation assays were used to develop the Global DNA Methylation Index (GDMI). The epigenome-wide arrays were used to identify 
gene-specific promoter regions differentially methylated in cancer, that can be quantified with methylation specific PCR (Supplementary Figure 1C).

\section{Global DNA methylation and gastric cancer}

We observed an inverse association (non-parametric trend test for ordered groups $p<0.0001$ ) between global DNA methylation in gastritis patients without metaplasia $($ mean $=5.74)$, gastritis patients with metaplasia $($ mean $=4.80)$, and gastric cancer cases $($ mean $=3.38)$ respectively. ( $F$-test $p<0.0001$, Scheffe test $p<0.0001$, when comparing gastritis patients without metaplasia against GC cases) (Figure 1). In order to assess the GDMI in high-risk GC clinics, we identified global methylation $>=6.5$ to be associated with gastritis in a random subset of patients that constituted our discovery set $(n=80)$. Using this criterion for identifying gastric cancer cases in our validation set $(n=180)$ resulted in $84.78 \%$ sensitivity and $32.82 \%$ specificity with $86.00 \%$ negative predictive value (NPV) and $30.71 \%$ positive predictive value (PPV) $(p=0.023)$. The same cutoff value for GDMI identified metaplasia $>=10$ percent with $87.50 \%$ sensitivity, $35.09 \%$ specificity, 95.24\% NPV and $15.91 \%$ PPV ( $p=0.089)$. (Supplementary Table 3) When considering the entire data including discovery and validation sets, we identified global methylation $>=9$ as the best cutoff point with $100 \%$ sensitivity and $100 \%$ NPV.

\section{Epigenome-wide DNA methylation analyses using bump hunting in samples from Peru}

\section{Gastritis $(n=20)$ vs gastric adenocarcinoma $(n=10)$}

We used the bump hunting method to perform an epigenome-wide analysis of the gastric cancer methylome and identify differentially methylated regions (DMRs) of biological interest using methylation arrays [33, 34]. For epigenome-wide DNA methylation array studies with small sample size ( $n=3$ in each group), bump hunting is the only recommended method for analysis when DNA methylation levels are correlated across $\mathrm{CpG}$ loci, as they are in cancer [35]. We found 500 statistically significant DMRs (FWER $p<0.05$ ) when we performed epigenomewide DNA methylation analyses comparing gastritis $(n=20)$ and cancer $(n=10)$ from Perú. Most of the DMRs were observed in chromosome $6(10 \%)$ followed by chromosome $1(9 \%)$, chromosome $19(8 \%)$, chromosome $2(7 \%)$, chromosome 7 (6\%), and chromosome $5(6 \%)$. None of the other chromosomes had more than 5\% DMRs. We found the DMRs across the following regions of the genome: inside the gene -431 DMRs $(43 \%)$; promoter region - 178 DMRs (18\%); overlaps 5' region - 165 DMRs (16\%); downstream from TSS - 114 DMRs (11\%); upstream from TSS - 111 DMRs (11\%). The number of individual CpGs per DMR ranged from 1 to 18 . Most of the DMRs had fewer than 10 CpGs (97\%). The DMRs with more than $10 \mathrm{CpGs}$ were found overlapping the downstream region of the first exon (16 DMRs), inside the exon (5 DMRs), covering the exon (3 DMRs), overlapping the upstream region of the first exon (1 DMR), inside the intron (1 DMR), and overlapping two exons (1 DMR).

\section{Epigenome-wide DNA methylation analyses using bump hunting in samples from TCGA}

We found 695 statistically significant DMRs (FWER $p<0.05)$ when we performed epigenome-wide DNA methylation analyses comparing normal $(n=11)$ and cancer $(n=295)$ samples from TCGA. Most of the DMRs were observed in chromosome $1(12 \%)$ followed by chromosome $6(9 \%)$ and chromosome $2(7 \%)$. We found the DMRs across the following regions of the genome: inside the gene - 135 DMRs (53\%); promoter region 58 DMRs (23\%); overlaps 5' region - 30 DMRs (12\%); downstream from TSS - 19 DMRs (7\%); upstream from TSS - 11 DMRs (4\%). The number of individual CpGs per DMR ranged from 1 to 10 . Most of the DMRs had fewer than 4 CpGs (94\%). The DMRs with more than 4 CpGs were found overlapping the downstream region of the first exon (8 DMRs), inside the exon (6 DMRs), inside the intron (3 DMRs), and covering the exon (1 DMR).

\section{Gene-specific DNA methylation in DMRs associated with gastric cancer in Peru and TCGA datasets}

We used qMSP to confirm promoter methylation in four of the 390 statistically significant DMRs (FWER $p<0.05)$ common to both the Peru and TCGA sample sets: IRF4, ELMO1, CLIP4 and MSC. Interestingly, there is very little difference in the genomic coordinates seen in the $\mathrm{X}$-axis of the scatterplots that draw the significant ELMOI and MSC DMRs identified by two separate epigenome-wide analyses of the samples from Peru and TCGA, performed with the bump hunting algorithm in minfi (Figure 2). This overlap in genomic coordinates for DMRs identified by separate epigenome-wide analyses of samples from patients with different ethnic, racial and socio-economic characteristics, suggest that promoter methylation of ELMOI and MSC, may track biological changes associated with adenocarcinoma, regardless of life-style and environmental exposures.

Natural $\log$ values of promoter methylation in IRF4, ELMO1, CLIP4 and MSC quantified with qMSP, increase with age but are not gender dependent (Supplementary Figure 2). Additionally, promoter methylation levels for all four genes are highly correlated among themselves, suggesting the possibility they share a common epigenetic clustering factor in their clonal evolution (Supplementary Table 4). Promoter methylation of IRF4 $(p<0.001)$, ELMO1 $(p<0.001)$, CLIP4 $(p<0.001)$, and MSC $(p<0.001)$, is strongly associated with increasing severity 
of disease in the histological progression from gastritis with no metaplasia, to gastritis with metaplasia, to gastric adenocarcinoma (Figure 3). Using logistic regression, we observed a statistically significant association between gastritis patients with metaplasia $>=10 \%$ and promoter methylation of IRF4, ELMOI and MSC, after adjusting for age and sex. We also observed a statistically significant association between gastric cancer diagnosis and promoter methylation of IRF4, ELMO1, CLIP4 and $M S C$, after adjusting for age and sex (Table 1). Together these results suggest that promoter methylation of IRF4, ELMO1, CLIP4 and MSC may be part of a gastric cancer $\mathrm{CpG}$ island methylator phenotype (CIMP). The concept of CIMP)was introduced to refer to a subset of colorectal carcinomas (CRCs) with widespread methylation of numerous promoter $\mathrm{CpG}$ island loci. Akin to microsatellite instability (MSI), CIMP is now recognized as one of the most important molecular carcinogenesis pathways of CRCs, and CIMP-high (CIMP-H) CRCs have been characterized for their clinicopathological features [36].

\section{Predictive models with gene-specific methylation}

We used the gene specific methylation association with gastric cancer within the discovery dataset $(n=116)$ to estimate separate screening models using IRF4, ELMO1, CLIP4 or MSC to classify participants in the validation set who were identified as having a high risk of gastric cancer based on a GDMI $<6.5$. This resulted in $74 \%$ correct classification as indicated in Table 2.

\section{Subset analysis of patients misdiagnosed by endoscopists}

Endoscopists diagnosed a total of 201 patients with high-risk gastric cancer. More than half of the patients $(53 \%)$ were diagnosed as gastric cancer patients $(n=80)$ by endoscopists. Pathologists at two separate institutions subsequently revised the diagnosis in 30 of the 80 cancer patients $(37.5 \%)$ diagnosed by the endoscopists in highrisk clinics, as gastritis patients, using the updated Sydney system for the histologic classification of gastritis. Thus, subset analysis was performed on 50 gastric adenocarcinoma patients in the case study group and 151 gastritis patients in the control study group.

We found that the GDMI discriminates between diagnosis of gastric cancer and gastritis by endoscopists. As can be seen in Figure 4A, global DNA methylation levels were significantly lower in gastric cancer cases than in gastritis controls $(p=0.002)$. The mean GDMI for the controls was $5.7(95 \% \mathrm{CI}, 4.93-6.41)$ and the mean GDMI for the cases was 3.7 (95\% CI, 2.99-4.39). The summary statistics for this comparison are listed in the Supplementary Table 5.

The pathological characteristics of the gastritis patients comprising the control study group are summarized in Supplementary Table 6. The revised Sydney system for classification of gastritis patients was used to distinguish between gastritis patients with superficial and deep Inflammation. Briefly, in gastritis patients with superficial inflammation the chronic active infiltration occupies the lamina propria between the gland crypts but remains above the glands necks. The glands do not show alterations. In gastritis patients with deep inflammation the chronic active infiltration extends beyond the gastric gland neck, occupying the space between the glands. The glands themselves do not show alterations. Gastritis patients with deep inflammation had a larger percentage of moderate and severe inflammation, a much higher frequency of atrophy and intestinal metaplasia, and a much lower incidence of helicobacter pylori (Supplementary Table 6).

We found that deep inflammation is associated with global DNA hypomethylation, a hallmark of human cancer: two-sided $p=.097$, one-sided $p=.0467$. (Figure 4B). The GDMI was able to discriminate gastritis patients

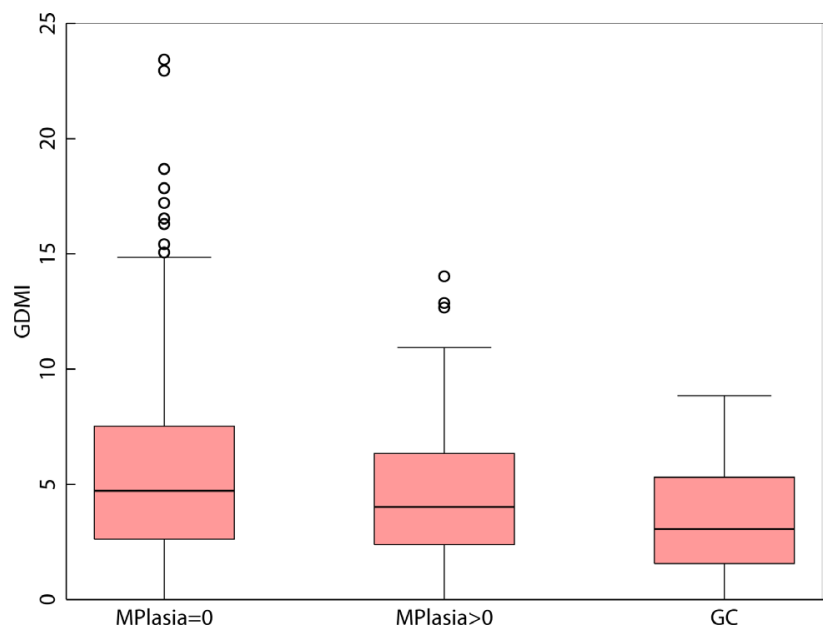

Figure 1: Boxplot of Global DNA Methylation Index levels in gastritis patients without metaplasia, gastritis patients with metaplasia and in patients diagnosed with adenocarcinoma of the stomach. 
according to the depth of inflammation: $t$-test $(p=0.01)$ and Mann-Whitney $(p=0.02)$. The mean GDMI for gastritis patients with superficial inflammation was 6.42 (95\% CI, 5.3-7.5) compared to 4.65 (95\% CI, 3.74-5.57) for those with deep inflammation. Furthermore, among gastritis patients with deep inflammation we found a significant association $(p=0.03)$ in the GDMI when comparing patients with and without intestinal metaplasia (Figure 4C). Gastritis patients with deep inflammation and intestinal metaplasia had significantly ( $p=0.03$ ) lower global DNA methylation levels (mean $=3.7,95 \%$ CI, 2.75-4.73) when compared to those without intestinal metaplasia (mean $=5.5,95 \% \mathrm{CI}, 3.98-6.93)$.
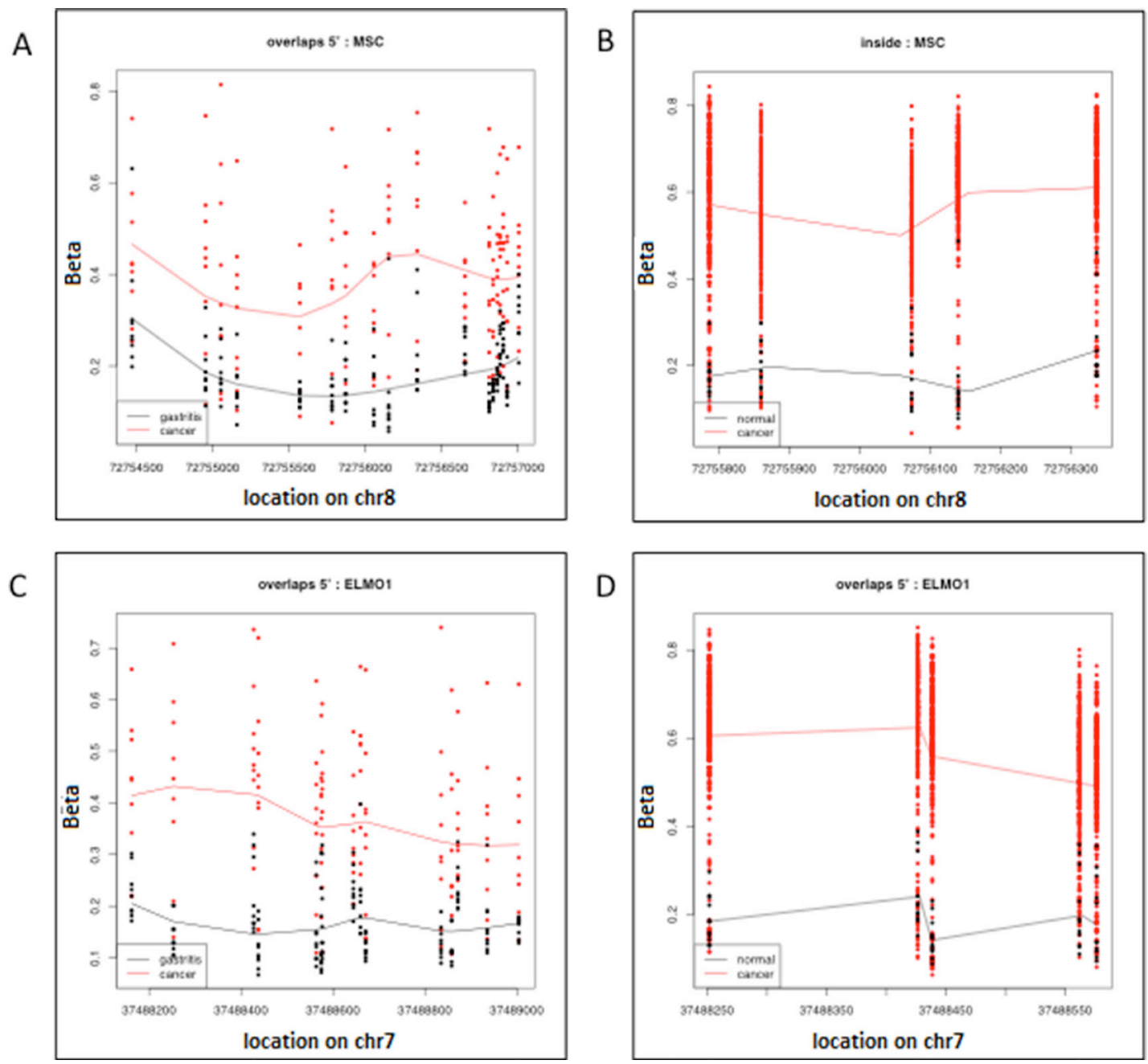

Figure 2: Significant Differentially Methylated Regions (DMR) identified with the bump hunting algorithm, as implemented in the minfi package from Bioconductor. Each row represents an individual CpG and each data point represents an individual patient. (A) Shows the DMR located on chromosome 8, which has the approximate genomic coordinates starting (72754500) and end (7275700) points. The genomic coordinates of this DMR correspond to the $5^{\prime}$ end of the Musculin (MSC) gene in the hg19 human genome build. This DMR was found to be differentially methylated when comparing the genome-wide epigenome of 10 gastric adenocarcinoma samples (red) and 20 gastritis samples (black) from patients seen in a high-risk gastric cancer clinic in Peru; (B) shows the differentially methylated CpGs (each row) located on chromosome 8 with approximate starting (72755800) and end (72756300) genomic coordinates. The genomic coordinates of this DMR correspond to the 5' end of the Musculin (MSC) gene and are located within the DMR in 1A. This DMR was found to be differentially methylated when comparing the genome-wide epigenome of 295 gastric adenocarcinoma samples (red) and 11 gastritis samples (black) from patients participating in the Cancer Genome Atlas (TCGA) project; (C) shows the DMR located on chromosome 8 with approximate starting (37488200) and end (37489000) genomic coordinates. The genomic coordinates of this DMR correspond to the 5' end of the Engulfment and Cell motility 1 (ELMO1) gene. This DMR was found to be differentially methylated when comparing the genome-wide epigenome of 10 gastric adenocarcinoma samples (red) and 20 gastritis samples (black) from patients seen in a high-risk gastric cancer clinic in Peru; (D) shows the differentially methylated CpGs (each row) located on chromosome 8 with approximate starting (37488250) and end (37488550) genomic coordinates. The genomic coordinates of this DMR correspond to the $5^{\prime}$ end of the Engulfment and Cell motility 1 (ELMO1) gene and are located within the DMR in (A). This DMR was found to be differentially methylated when comparing the genome-wide epigenome of 295 gastric adenocarcinoma samples (red) and 11 gastritis samples (black) from patients participating in the Cancer Genome Atlas (TCGA) project. 
Autosomal epigenome-wide analysis misdiagnosed gastritis $(n=10)$ vs gastric adenocarcinoma $(n=10)$

We found 1448 statistically significant DMRs (FWER $p<0.05$ ) when we performed epigenome-wide DNA methylation analyses comparing gastritis samples misdiagnosed as gastric adenocarcinoma by endoscopists $(n=10)$ and gastric adenocarcinoma $(n=10)$ from Perú. Most of the DMRs were observed in the X chromosome (36\%) followed by chromosome $6(6 \%)$ and the $\mathrm{Y}$ chromosome (6\%). None of the other chromosomes had more than 5\% DMRs. We found the DMRs across the following regions of the genome: inside the gene -639 DMRs (44\%); overlaps 5' region - 295 DMRs (20\%); promoter region - 260 DMRs (18\%); downstream from TSS - 133 DMRs (9\%); upstream from TSS - 118 DMRs (8\%). The number of individual CpGs per DMR ranged from 1 to 18. Most of the DMRs had fewer than $10 \mathrm{CpGs}$ (96\%). The DMRs with more than $10 \mathrm{CpGs}$ were found overlapping the downstream region of the first exon (39 DMRs), inside the exon (10 DMRs), and covering the first exon (5 DMRs).

\section{Autosomal epigenome-wide-misdiagnosed gastritis $(n=10)$ gastritis $(n=10)$}

We found 392 statistically significant DMRs (FWER $p<0.05)$ when we performed epigenome-wide DNA methylation analyses comparing gastritis $(n=10)$ and gastritis samples misdiagnosed as gastric adenocarcinoma by endoscopists $(n=10)$ from Perú. Most of the DMRs were observed in the $\mathrm{X}$ chromosome (27\%) followed by chromosome $6(10 \%)$ and chromosome $1(6 \%)$. None of the other chromosomes had more than 5\% DMRs. We found the DMRs across the following regions of the genome: inside the gene -428 DMRs $(46 \%)$; promoter region - 180 DMRs (19\%); overlaps 5' region - 139 DMRs (15\%); upstream from TSS - 93 DMRs (10\%); downstream from TSS - 82 DMRs (9\%). The number of individual CpGs per DMR ranged from 1 to 14. Most of the DMRs had fewer than 7 CpGs (96\%). The DMRs with more than CpGs were found overlapping the downstream region of the first exon (15 DMRs) and inside the first exon (11 DMRs).

\section{DISCUSSION}

Ours is the first study that combines global, epigenome-wide and gene-specific methylation analyses of the gastric cancer epigenome in endoscopic biopsies obtained from ambulatory high-risk gastric cancer clinics. Our findings suggest that promoter methylation of CLIP4, $I R F 4, E L M O 1$, and MSC, together with a GDMI > 4, is a useful molecular panel for gastric cancer risk stratification in endoscopic biopsies (Figure 5).

Promoter methylation of CAP-Gly Domain Containing Linker Protein Family Member 4 (CLIP4) is the only one, of the four genes in our panel, which has been reported as methylated in gastric cancer in previous
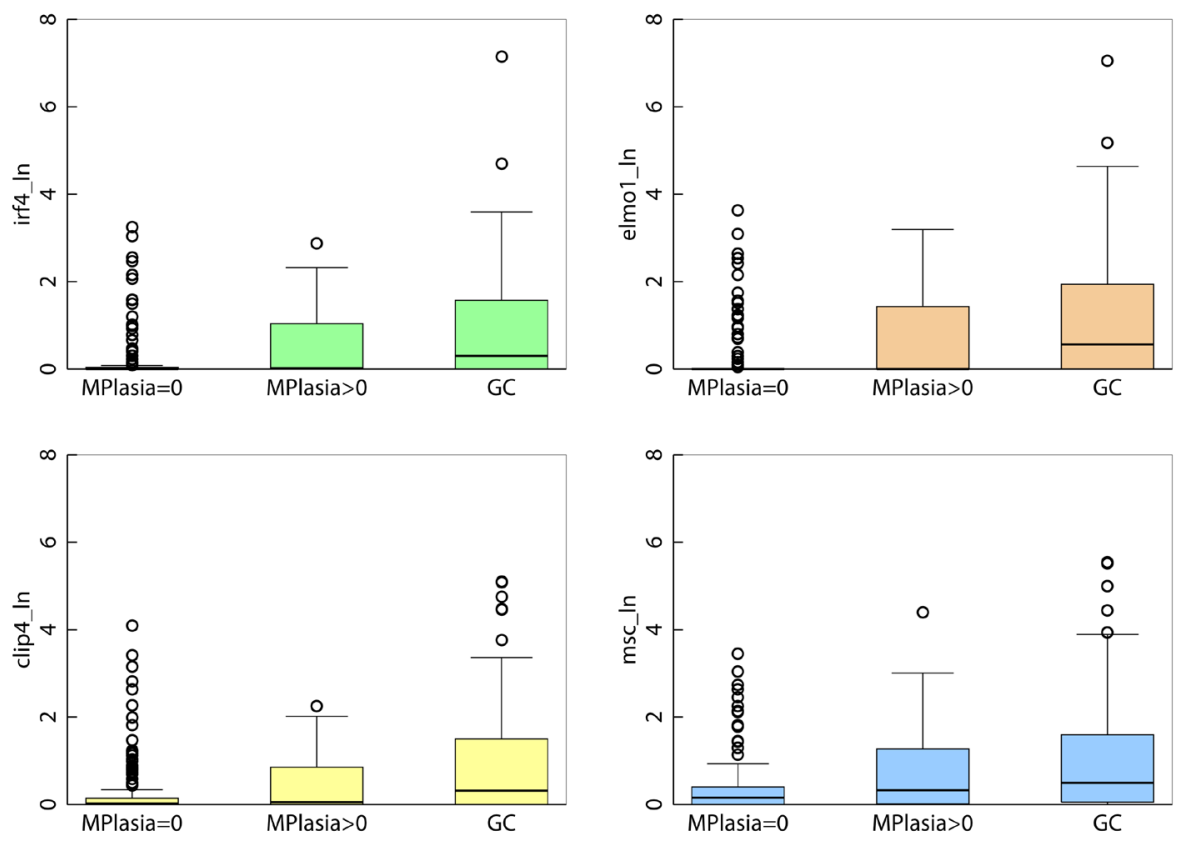

Figure 3: Boxplot of gene-specific promoter methylation in gastritis patients without metaplasia, gastritis patients with metaplasia and in patients diagnosed with adenocarcinoma of the stomach. 
Table 1: Promoter DNA methylation association with gastric cancer and metaplasia $>=10 \%$

\begin{tabular}{|c|c|c|c|c|c|c|}
\hline & Odds Ratio & Std. Err. & 95\% Conf. interval & Pseudo R2 & Obs & $\boldsymbol{P}$ \\
\hline \multicolumn{7}{|c|}{ Gastric cancer (unadjusted) } \\
\hline gmeth_ln & 0.49 & 0.10 & $0.32-0.73$ & 0.04 & 257 & $<0.0001$ \\
\hline IRF4_ln & 2.37 & 0.38 & $1.72-3.25$ & 0.10 & 291 & $<0.0001$ \\
\hline ELMO1_ln & 2.00 & 0.27 & $1.54-2.59$ & 0.06 & 286 & $<0.0001$ \\
\hline CLIP4_ln & 1.90 & 0.27 & $1.43-2.51$ & 0.07 & 290 & $<0.0001$ \\
\hline$M S C_{-} \ln$ & 1.76 & 0.24 & $1.35-2.30$ & 0.06 & 291 & $<0.0001$ \\
\hline \multicolumn{7}{|c|}{ Gastric cancer (age, sex adj) } \\
\hline gmeth_ln & 0.46 & 0.10 & $0.30-0.71$ & 0.09 & 249 & $<0.0001$ \\
\hline$I R F 4 \_\ln$ & 2.21 & 0.37 & $1.60-3.07$ & 0.12 & 276 & $<0.0001$ \\
\hline ELMO1_ln & 1.95 & 0.27 & $1.48-2.57$ & 0.12 & 271 & $<0.0001$ \\
\hline CLIP4_ln & 1.78 & 0.26 & $1.33-2.38$ & 0.09 & 275 & $<0.0001$ \\
\hline$M S C \_\ln$ & 1.67 & 0.24 & $1.26-2.21$ & 0.09 & 276 & $<0.0001$ \\
\hline \multicolumn{7}{|c|}{ Mplasia $>=10 \%$ (unadj) } \\
\hline gmeth_ln & 0.50 & 0.15 & $0.29-0.89$ & 0.04 & 183 & 0.018 \\
\hline IRF4_ln & 2.49 & 0.68 & $1.46-4.25$ & 0.08 & 188 & 0.001 \\
\hline ELMO1_ln & 2.44 & 0.55 & $1.57-3.79$ & 0.12 & 183 & $<0.0001$ \\
\hline CLIP4_ln & 2.08 & 0.53 & $1.27-3.41$ & 0.06 & 187 & 0.004 \\
\hline$M S C \_\ln$ & 2.61 & 0.64 & $1.61-4.24$ & 0.12 & 188 & $<0.0001$ \\
\hline \multicolumn{7}{|c|}{ Mplasia > = 10\% (age, sex adj) } \\
\hline gmeth_ln & 0.43 & 0.13 & $0.23-0.79$ & 0.09 & 176 & 0.007 \\
\hline$I R F 4 \_\ln$ & 1.89 & 0.58 & $1.03-3.44$ & 0.11 & 177 & 0.038 \\
\hline ELMO1_ln & 1.88 & 0.47 & $1.15-3.08$ & 0.13 & 172 & 0.012 \\
\hline CLIP4_ln & 1.57 & 0.43 & $0.92-2.69$ & 0.10 & 176 & 0.098 \\
\hline$M S C \_\ln$ & 1.98 & 0.54 & $1.17-3.36$ & 0.13 & 177 & 0.011 \\
\hline
\end{tabular}

studies. CLIP4, also known as UBASH3A or TULA, is a member of the T-cell ubiquitin ligand family and suppresses T-cell signaling. CLIP4 can facilitate growth factor withdrawal-induced apoptosis in T-cells [37] and promote the accumulation of various activated target receptors, such as T-cell receptors, epidermal growth factor (EGF) receptor, and platelet-derived growth factor beta-receptor [38, 39], which can induce cell invasiveness and metastasis. CLIP4 also activates the EGFR signaling pathway by downregulation of the EGF receptor [40]. In other cells, CLIP4 activates Syk [41], a member of the protein tyrosine kinase family linked with cell motility and increased cell migration [42-44].

Interferon regulatory factors (IRFs) are a family of transcriptional regulators defined by a characteristic homology in their DNA-binding domain. They play an important role in the regulation of various genes (such as IFNs, interleukins, MHC class I/II), apoptosis and differentiation/maturation $[45,46]$. Interferon regulatory factor $4(I R F-4)$ is one member with very restricted expression pattern and plays a crucial role in the function of immune cells. Predominately B- and activated T-lymphocytes are $I R F-4$ positive [47]. Deletion of $I R F-4$ causes failure to develop mature and functionally active B- and T-lymphocytes [48].

Engulfment and cell motility 1 (ELMO1) plays a role in promoting cancer cell migration and invasion in malignant glioma [49]. ELMO1 promoter methylation roles are also reported in human colorectal cancer [50], kidney disease [51], and rheumatoid arthritis [52]. The protein produced by ELMOI belongs to a protein family that interacts with dedicator of cytokinesis proteins to promote phagocytosis and cell migration.

Musculin, a human protein encoded by the MSC gene, is a transcriptional repressor capable of binding an E-box element either as a homodimer or as a heterodimer with E2A in vitro. The encoded protein also forms heterodimers with E2A proteins in vivo. This protein is capable of inhibiting the transactivation capability of E47, an E2A protein, in mammalian cells. This gene is a downstream target of the B-cell receptor signal transduction pathway [53, 54]. MSC (and probably TCF21) is located together with TBX1 and PITX2 upstream of myogenic regulatory factor 5 (Myf5) and Myogenic Differentiation 1 (MyoD 1). MSC regulates the levels of expression of $M y f 5$ and $M y o D$ by direct 
Table 2: Odds ratios and coefficient of models predicting GC risk using IRF4, ELMO1, CLIP4 or MSC

\begin{tabular}{cccccccccc}
\hline & OR & SE & \multicolumn{2}{c}{$\mathbf{9 5 \%}$ Conf int } & Coef & SE & \multicolumn{2}{c}{ 95\% Conf int } & $P$ \\
\hline IRF4 & 1.398 & 0.236 & 1.003 & 1.947 & 0.335 & 0.169 & 0.003 & 0.667 & 0.048 \\
const & & & & & -0.317 & 0.208 & -0.723 & 0.09 & 0.127 \\
ELMO1 & \multirow{2}{*}{1.195} & \multirow{2}{*}{0.104} & \multirow{2}{*}{1.007} & 1.418 & 0.178 & 0.087 & 0.007 & 0.349 & 0.041 \\
const & & & & & -0.293 & 0.211 & -0.706 & 0.121 & 0.166 \\
CLIP4 & \multirow{2}{*}{1.136} & \multirow{2}{*}{0.091} & \multirow{2}{*}{0.971} & \multirow{2}{*}{1.328} & 0.127 & 0.08 & -0.029 & 0.284 & 0.111 \\
const & & & & & -0.225 & 0.203 & -0.624 & 0.174 & 0.269 \\
MSC & \multirow{2}{*}{1.249} & \multirow{2}{*}{0.155} & \multirow{2}{*}{0.979} & \multirow{2}{*}{1.594} & 0.223 & 0.124 & -0.208 & 0.466 & 0.073 \\
const & & & & & -0.334 & 0.216 & -0.756 & 0.09 & 0.123 \\
\hline
\end{tabular}

interactions through ubiquitin-activating enzymes E1 C-terminal related $(E C R-1)$ and the distal regulatory region (DRR), respectively [55]. Methylation of Musculin has not been previously reported.

Methylation of individual dinucleotide cytosineguanosine motifs $(\mathrm{CpG})$ in $\mathrm{CpG}$ islands located in promoter regions, is one of the mechanisms of gene regulation in mammals and a common event of gene silencing in cancer. Gain of methylation of $\mathrm{CpG}$ islands together with global loss of methylation are frequently observed events in every tumor cell, in contrast to normal cells $[56,57]$. De novo DNA methylation of genes with important cellular regulatory functions, such as cell cycle, DNA repair, apoptosis and tumor suppressor genes, is involved in tumorigenesis [58-60].

Several gene specific DNA methylation events seen in gastritis and gastric cancer patients may be associated with Helicobacter pylori infection and the progression of dysplastic lesions to adenocarcinoma of the stomach, but the evidence is contradictory and non-conclusive yet. Promoter methylation in a subset of gastric cancer patients is associated with the $\mathrm{CpG}$ island methylator phenotype, which includes methylation of such genes as CDKN2A and hMLH1 [61, 62]. Promoter methylation in Helicobacter pylori or Epstein-Barr virus infected gastric mucosae may play a functional role and lead to gastric cancer risk [27, 63-65]. Inactivation of COX-2, HMLH1 and CDKN2A by promoter methylation depends on the Helicobacter pylori genotype and occurs by distinct pathways, according to the histological subtype and tumor location [66].

Promoter methylation of MGMT is related to gastric cancer risk, distant metastasis, and lymph node metastasis, which indicates that MGMT promoter methylation may play an important role in gastric cancer development [67]. Promoter methylation of ASC/TMS1 is associated with poor prognosis of patients with gastric cancer [68]. $R B L 1$ is methylated in patients with intestinal metaplasia, with or without Helicobacter pylori, and in gastric cancer patients [69]. Promoter methylation of RNF180 is associated with Helicobacter pylori infection and serves as a marker for gastric cancer and atrophic gastritis [70].
Promoter methylation of $R N F 180, D A P K 1$ and $S F R P 2$ can be detected in plasma DNA of patients with gastric cancer [71]. Promoter methylation of E-cadherin in a subset of our gastric cancer patients is consistent with aggressiveness and metastasis of gastric cancer [72]. $H L T F$ methylation plays a role in the early stages of gastric carcinogenesis in patients with family histories and may be a valuable susceptible marker for the risk of gastric cancer in individuals with family predisposition [73].

Several studies have been carried out examining altered methylation levels in normal gastric mucosa and GC attempting to identify possible biomarkers for the surveillance of high-risk patients. Bernal et al., showed that aberrant hypermethylation of the Reprimo gene represents a potential biomarker for the early detection of gastric cancer with differential methylation in the plasma DNA between controls and cases. Moreover, the signetring cell-type of $\mathrm{GC}$ was associated with a methylation profile of eight specific genes [74]. Also, promoter methylation levels are correlated with loss of expression of Reprimo in gastric cancer tissues, progression from stage I to stages II-IV and lymph node metastasis [75].

Other studies, using epigenome-wide DNA methylation arrays for discovery and qMSP for validation, unveiled the role of promoter methylation in in endoscopic samples taken from high-risk clinics patients diagnosed with gastritis and gastric carcinogenesis. Shin et al. reported the promoter methylation of $M O S, D C C, C R K$, and PTPN6 in gastric cancer [76]. Epigenome-wide DNA methylation arrays have also identified the role of DVL2 and ETS1 methylation in diffuse- and mixed-types of early gastric cancers [77]. On the other hand, C19orf35 and CNRIP1 were related to the diffuse type rather than intestinal type, and GAL3ST2 and ITGA3 were related to the mixed-type rather than the other two types [77]. The methylation of other genes, CLIP4, XKR6, CCDC57, MAML3 and SDC2, was related with one or more of the following variables: age, tumor location, and Helicobacter pylori infection, rather than with the histologic subtype [77].

We also investigated the role of GDMI as biomarker for gastric cancer carcinogenesis. The lower GDMI levels 

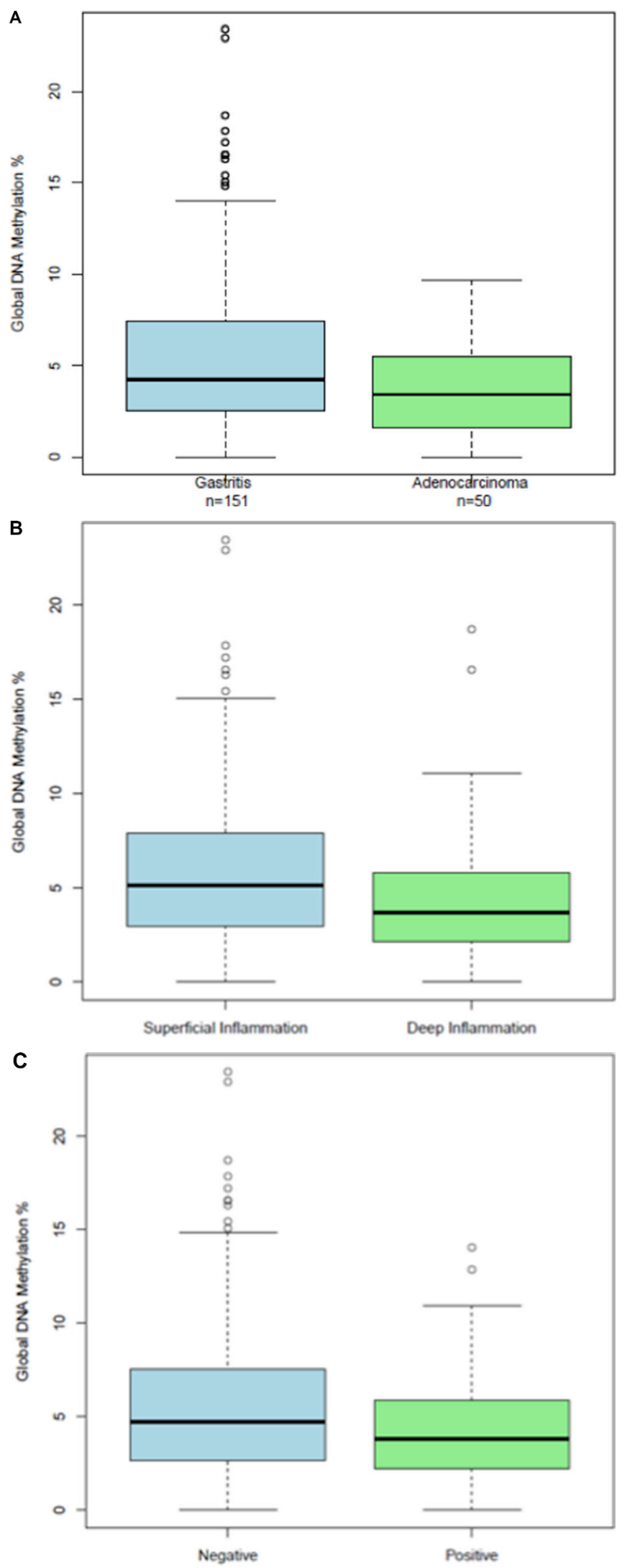

Figure 4: (A) Boxplots of Global DNA Methylation Index levels in a subset of adenocarcinoma cases and gastritis controls that were diagnosed by endoscopists in the clinic; (B) Boxplots of Global DNA Methylation Index levels in a subset of gastritis patients dichotomized according to the depth of superficial and deep inflammation; (C) Boxplots of Global DNA Methylation Index levels in deep inflammation cases according to the presence of intestinal metaplasia. 
we observed in gastric cancer biopsies are consistent with the observations made by Lee et al, namely that gastric epithelial dysplasia and intramucosal cancer tissues had significantly lower levels of LINE-1 methylation than adjacent normal gastric tissues [26]. LINE-1 is a surrogate marker of global DNA methylation that measures methylation in a subset of repetitive elements across the genome. The GDMI is a better indicator of global DNA methylation levels than LINE1, because it quantifies DNA methylation across the entire human genome. Our study further shows that the GDMI can discriminate gastritis patients with different degrees of inflammation and metaplasia. This interesting molecular difference suggests the ability to potentially discriminate between different degrees of gastritis severity, intestinal metaplasia and gastric adenocarcinoma, solely based on global DNA methylation levels in gastric mucosa epithelium.

The GDMI can discriminate the depth of inflammation, as gastritis patients with deep inflammation exhibit lower GDMI than those with superficial inflammation, suggesting that at the molecular levels these patients may be the most prone to progress towards gastric cancer. We also observed interesting results when contrasting patients with intestinal metaplasia less than or greater than $10 \%$. Patients with intestinal metaplasia $>=10 \%$ had lower GDMI $(p=0.013)$. We also found that the gastritis patients who were originally diagnosed with cancer by the endoscopists harbor lower GDMI values than the gastritis patients, classified as such by both the endoscopists and the pathologists. Furthermore, these gastritis patients misdiagnosed as cancer patients by endoscopists had a similar global DNA methylation profile as adenocarcinoma patients. These data support the notion that the misdiagnosed cases have an underlying oncogenic molecular process and are most likely to deteriorate to cancer. It should be noted that in all of our models of gastric cancer, sex was a significant covariate while age was not. This does not reflect absence of association between gastric cancer and age, but rather the correlation between age and GDMI, which partially accounts for the covariation between age and the outcome, masking some of the contribution by age. By contrast, sex and GDMI were independent.

Only a few studies have examined global DNA hypomethylation in gastric cancer by itself, under the rationale that hypomethylation is the earliest epigenomic event that signifies the transition from a normal to a malignant phenotype. While the precise mechanisms that lead to a global loss of methylation patterns in cancer are still to be elucidated, it is evident that global DNA hypomethylation is already present in the early stages of gastric carcinogenesis and may play various roles in the biologic progression of gastric cancer lesions. Genome wide hypomethylation and regional hypermethylation have been shown to occur in an enlarged-fold gastritis that may also contribute to the tumorigenesis of diffuse-type gastric cancers [78]. Another study found that global DNA hypomethylation, assessed by incubating DNA with $(3 \mathrm{H})$-S-adenosylmethionine and Sss 1 methylase, also occurs in the early stages of gastric carcinogenesis up to chronic atrophic gastritis, but is lost as a marker in gastric cancer. They also found that global hypomethylation of DNA increased substantially with severe atrophy $(p=0.01)$ or
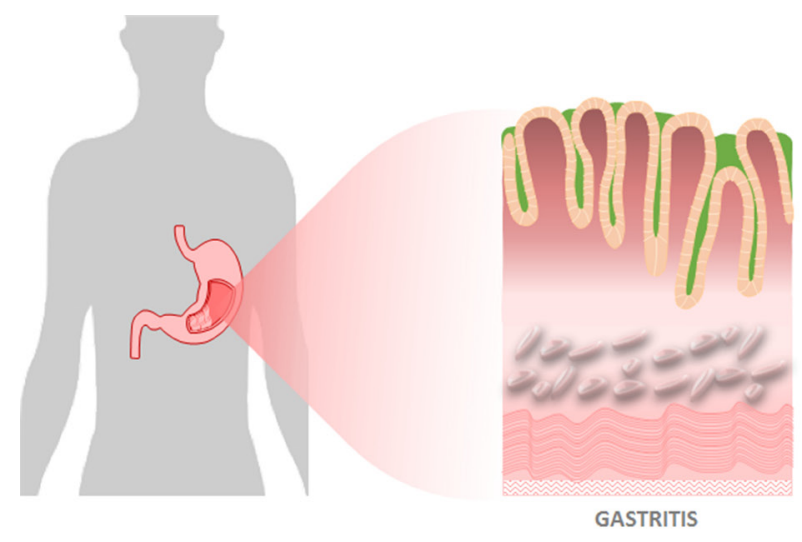

GASTRITIS

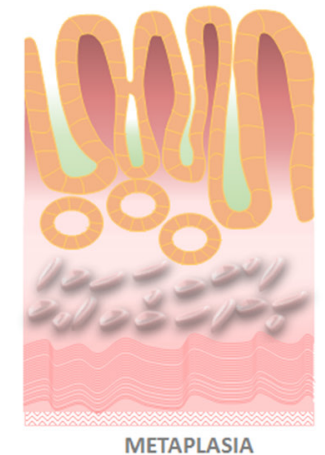

METAPLASIA

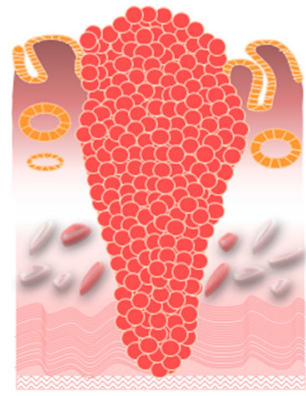

GASTRICCANCER
$P$ values Gastritis vs GC

$\begin{array}{rlll} & & & \\ \text { GLOBAL METHYLATION } & \text { MEAN: } 5.74 & \text { MEAN: } 4.80 & <0.001 \\ & & & \\ \text { SPECIFIC METHYLATION } & & & \\ \text { IRF4 } & \text { MEAN: } 0.69 & \text { MEAN: } 1.68 & \text { MEAN: } 16.96 \\ \text { ELMO1 } & \text { MEAN: } 1.09 & \text { MEAN: } 3.77 & \text { MEAN: } 19.60 \\ \text { CLIP4 } & \text { MEAN: } 1.27 & \text { MEAN: } 1.48 & \text { MEAN: } 8.84 \\ \text { MSC } & \text { MEAN: } 1.08 & \text { MEAN: } 4.97 & <0.001 \\ \text { MEAN: } 10.92 & <0.001\end{array}$

Figure 5: Graphical representation of histologic and molecular progression stages proposed for gastric adenocarcinoma, with mean values for global and gene-specific promoter methylation of IRF4, ELMO1, CLIP4 and MSC. 
with type III intestinal metaplasia $(p=0.15)$, thus leading the authors to propose it as a useful biomarker of gastric neoplasia, and monitoring the response to chemopreventive agents [79]. Another study found that LINE-1 hypomethylation is significantly associated with $H$. pylori infection, supporting a role for LINE-1 methylation level as viable epigenetic marker of gastric mucosae induced by $H$. pylori infection [31]. Collectively, these studies suggest that the GDMI may be an epigenomic reflection of important early cellular events in gastric cancer initiation and progression $[80,7]$.

Much as with mutational data, our data on global, epigenome-wide and promoter DNA methylation alterations in gastric premalignant lesions, should encourage further analyses of differential methylation in specific genetic loci associated with over and under expression in signaling pathways that contribute to gastric cancer development or progression, and how these loci match or differ from those implicated in other types of cancers, all of which in turn could have implications for development of new early detection and diagnostic tools for the precision medicine era.

\section{MATERIALS AND METHODS}

\section{Participants}

The study population consists of a prospective, observational cohort initiated in 2006 and closed in June 2009. We recruited 576 patients who were seen by gastrointestinal endoscopists in high-risk gastric cancer clinics of the Gastroenterology Divisions at three hospitals in Lima: Hospital Nacional Arzobispo Loayza, Hospital Nacional Dos de Mayo, and the cancer-specialized Instituto Nacional de Enfermedades Neoplásicas. The inclusion criterion for the gastritis controls in the study was for the patients to have gastro-duodenal symptoms (ICD9-CM code 535) whereas for the cases, the inclusion criterion was to have a clinical diagnosis of gastric cancer (ICD9-CM code 151), all determined by pathologists at two different institutions in Peru. A pathologist at Johns Hopkins School of Medicine reviewed a random sample of slides. All patients underwent endoscopic diagnosis and biopsy. From this cohort, 376 study patients had DNA samples adequate for analysis. Participants were randomly assigned to three groups: a Discovery group for GDMI analysis; a Discovery group for epigenome-wide and genespecific DNA methylation analysis; and a Validation group for combined GDMI and gene-specific promoter DNA methylation analysis. The Institutional Review Boards of the Instituto Nacional de Neoplásicas, the National Hospital Arzobispo Loayza, the Hospital Nacional Dos de Mayo, the Universidad Peruana Cayetano Heredia and the Johns Hopkins School of Medicine (NA_00020633) approved the research protocols. Informed written consent was obtained from all patients included in the study.

\section{Tissue samples and DNA extraction}

Two endoscopy biopsies were taken from each patient. Biopsies were obtained from the cancerous lesion for the cases and from the gastric antrum for the controls, frozen at -70 and sent for processing and storage in the Universidad Peruana Cayetano Heredia. Gastric mucosa tissue was fixed in 10\% formalin buffer and embedded in paraffin for microscopy histological examination. Hematoxylin and eosin-stained histological slides were scored using the Sydney System (Lash, 2013 \#166). Biopsies indicative of intestinal metaplasia were stained with PAS. H. pylori lesions were identified by Warthin Starry silver stain. All neoplastic tissues used in this study were classified as gastric adenocarcinoma by histopathology.

DNA was extracted from the frozen tissue samples using the QIAmp DNA Mini Kit (QIAGEN, Germany) and stored at $-20^{\circ} \mathrm{C}$ until use in the Universidad Peruana Cayetano Heredia. DNA concentrations were measured using Nanodrop ND-1000 spectrophotometer. Five micrograms of DNA were sent to Johns Hopkins University for DNA methylation analyses.

\section{Global DNA methylation analysis}

Global DNA methylation levels were determined by ELISA using the MDQ1, Imprint ${ }^{\circledR}$ Methylated DNA Quantification Kit (Sigma, USA) according to the manufacturer's instructions. Each analysis for sample(s) and control DNA was performed in duplicate and the average of the absorbance readings at $450 \mathrm{~nm}\left(\mathrm{~A}_{450}\right)$ was used for calculations. The GDMI for each sample was calculated according to the equation: $\left[\left(\mathrm{A}_{450 \mathrm{av}}\right.\right.$ Sample $-\mathrm{A}_{450 \mathrm{av}}$ Blank $) /$ $\left(\mathrm{A}_{450 \mathrm{av}}\right.$ Methylated Control DNA - $\mathrm{A}_{450 \mathrm{av}}$ Blank)] $\times 100$.

\section{Epigenome-wide DNA methylation analysis}

The HumanMethylation450K DNA BeadChip assay was used to perform unbiased epigenome-wide DNA methylation analysis. Bisulfite modification of genomic DNA $(2 \mu \mathrm{g})$ was performed with EpiTect Bisulfite Kit (QIAGEN) according to the manufacturer's protocol. We hybridized bisulfite converted DNA to the HumanMethylation $450 \mathrm{~K}$ array to identify differentially methylated regions (DMRs) in gastritis samples $(n=10)$, gastritis samples misdiagnosed as cancer by endoscopists $(n=10)$ and cancer samples $(n=10)$. To validate these results we performed an unbiased epigenome-wide DNA methylation analysis to identify DMRs in gastric cancer samples $(n=295)$ from the Cancer Genome Atlas project (TCGA) and gastritis controls $(n=20)$ from Perú.

We imported the data into $\mathrm{R}$ using the illuminaio package [81]. For data normalization we used the minfi package to apply the Noob background subtraction and dye-bias correction [82] followed by normalization and 
identification of DMRs between cases and controls using the bump hunting method in minfi [83]. The minfi package provides tools for analyzing Illumina's methylation arrays and includes methods for preprocessing, quality assessment, and detection of differentially methylated regions from the kilobase to the megabase scale. We performed pre-processing with the minfi package applying a version of subset quantile normalization to the Meth and Unmeth intensities separately. The distribution of type I and type II probes were forced to be the same by first quantile normalizing the type II probes across samples and then interpolating a reference distribution to which the type I probes are normalized. The stratified quantile normalization method is implemented by the preprocessQuantile function (the function does no background correction and removes zeros using the fix2 MethOutlier function). This algorithm relies on the assumptions necessary for quantile normalization and involves both within and between sample normalization. After normalization the bump hunting method was carried out by first fitting a linear regression model for each locus before smoothing the coefficient within clusters along the genome to identify bumps. More specifically, for each locus, a linear model was used to estimate the coefficient of difference in methylation levels between the cancer group and the normal groups. After fitting the linear regression model, the bump hunting method was implemented to estimate the regions for which there were statistically significant differences in methylation levels (Differentially Methylated Regions or DMRs) between the cancer group and the normal groups. Statistical uncertainty was assigned to each DMR using permutation tests generate a raw $p$-value from the bump hunting method, and an adjusted $p$-value generated from the minfi package using Storey's procedure (bump hunting $q$-value). We then intersected the statistically significant DMRs (FWER $p<0.05)$ that discriminate gastric cancer from gastritis in samples from Peru and TCGA.

\section{Gene-specific DNA methylation analyses}

We selected four of the genes that had the greater variance and the largest number of CpGs in the DMR window, from the list of significant DMRs (FWER $p<0.05)$ common to both the DMR results from the Peru and TCGA epigenome-wide analyses: IRF4 (interferon regulatory factor 4); ELMO1 (encodes Engulfment and cell motility protein 1); CLIP4 (CAP-Gly domain containing linker protein family member 4); and $M S C$ (encoding Musculin protein). We designed primers and probes to quantify promoter methylation of these four genes using fluorogenic quantitative methylation specific PCR (qMSP), as previously described [84].

Briefly, bisulfite-modified DNA was used as a template for qMSP. The genomic sequence for the genes within the DMRs identified with the bump hunting algorithm and 1000 bases up- and downstream was obtained from the UCSC Genome Browser [85]. The primers and hybridization probes for methylation analysis were designed based on this sequence by using MethPrimer [86]. All primer and probe sequences are listed in Supplementary Table 8. Fluorogenic PCR reactions were performed in duplicates in a reaction volume of $20 \mu \mathrm{l}$ that contained $3 \mu \mathrm{l}$ of bisulfite-modified DNA; $600 \mathrm{nM}$ of each primer; $200 \mathrm{nM}$ probe; $0.75 \mathrm{U}$ of platinum Taq polymerase (Invitrogen, MD, USA); $200 \mu \mathrm{M}$ of each dATP, dCTP, dGTP and dTTP; $200 \mathrm{nM}$ ROX dye reference; $1 \mathrm{X}$ buffer (16.6 mM ammonium sulfate; $67 \mathrm{mM}$ Trizma [Sigma]; $6.7 \mathrm{mM}$ of magnesium chloride; $10 \mathrm{mM}$ of mercaptoethanol and $0.1 \%$ dimethyl-sulfoxide). Amplifications were performed using the reaction profile: $95^{\circ} \mathrm{C}$ for $3 \mathrm{~min}$, followed by 50 cycles at $95^{\circ} \mathrm{C}$ for $15 \mathrm{~s}$ and $60^{\circ} \mathrm{C}$ for $1 \mathrm{~min}$ in a $7900 \mathrm{HT}$ sequence detector (Applied Biosystems, CA, USA) and were analyzed by a sequence detector system (SDS 2.4; Applied Biosystems).

\section{Statistical analysis}

Patients with adequate samples for analysis were randomly divided into a Discovery cohort for separate global DNA methylation $(n=80)$ and gene-specific DNA methylation $(n=116)$ analyses and a Validation cohort for combined global and gene-specific DNA methylation analyses (Supplementary Figure 3). The revised Sydney criteria were used for gastritis classification (Lash, 2013 \#166). Analyses were adjusted for Helicobacter pylori infection status, age and sex. Disease status was a binary variable indicating gastritis vs gastric adenocarcinoma based on pathological diagnosis. Subset analyses were performed in a subset of samples that were misdiagnosed by endoscopists. Global DNA methylation was measured on genomic DNA and analyzed as a continuous variable. Epigenome-wide and gene-specific DNA methylation was measured on bisulfite converted DNA and analyzed as continuous variables. Quantitative methylation specific PCR was used to measure promoter methylation of IRF4, ELMO1, and MSC.

The primary outcome indicator was a binary variable to identify gastric adenocarcinoma (GC) from gastritis cases. We also used the level of metaplasia as a proxy to identify gastritis patients with higher risk of developing GC. We conducted ordinary and logistic regression and analysis of variance, Fisher exact test and other tests of hypothesis to analyze the data. All data was analyzed and managed using STATA 13 (Statacorp, Texas, USA) and results with a $p<0.05$ were considered as statistically significant. Student's $t$-test or ANOVA test were used for analyzing distributions or variances, respectively. Additional global and epigenome-wide analyses were performed in subset of patients from Peru $(n=201)$ for whom we also had a diagnosis provided by the endoscopists. In addition, epigenome-wide analyses were 
performed in 295 gastric cancer samples and 11 normal gastric epithelium samples from the Cancer Genome Atlas (TCGA) project.

\section{Abbreviations}

GDMI, Global DNA Methylation Index; GC, Gastric cancer; NBI, Narrow-band imaging; LINEs, Long interspersed nuclear elements; Helicobacter pylori

\section{ACKNOWLEDGMENTS AND FUNDING}

This research was supported in part by National Cancer Institute grants K01-CA164092 and U01CA84986; Proyecto de Atracción de Capital HumanoModalidad de Estadía Corta - Comisión Nacional de Ciencia y Tecnología (CONICYT), Chile (RGP); FONDECYT $\mathrm{N}^{\circ} 11150802$ and FONDECYT $\mathrm{N}^{\circ} 11150622$; E. Soudry is recipient of a fellowship grant from the American Physicians Fellowship for Medicine in Israel. Dr. Berg is supported by grants R21 AI078237 and R21 AI088337 from the US National Institute of Health.

\section{CONFLICTS OF INTEREST}

D. Sidransky owns MDxHealth (formerly Oncomethylome Sciences, SA) stock, which is subject to certain restrictions under University policy. D. Sidransky is a paid consultant to MDxHealth, and is a paid member of the company's Scientific Advisory Board. The Johns Hopkins University in accordance with its conflict of interest policies is managing the terms of this arrangement.

\section{REFERENCES}

1. Ferlay J, Soerjomataram I, Dikshit R, Eser S, Mathers C, Rebelo M, Parkin DM, Forman D, Bray F. Cancer incidence and mortality worldwide: sources, methods and major patterns in GLOBOCAN 2012. Int J Cancer. 2015; 136:E359-386.

2. Asaka M, Dragosics BA. Helicobacter pylori and gastric malignancies. Helicobacter. 2004; 9:35-41.

3. Atherton JC. The pathogenesis of Helicobacter pyloriinduced gastro-duodenal diseases. Annu Rev Pathol. 2006; 1:63-96.

4. Voutilainen ME, Juhola MT. Evaluation of the diagnostic accuracy of gastroscopy to detect gastric tumours: clinicopathological features and prognosis of patients with gastric cancer missed on endoscopy. Eur J Gastroenterol Hepatol. 2005; 17:1345-1349.

5. Yie SM, Ye SR, Ma XL, Xie K, Zhang JB, Cao M, He X, $\mathrm{Hu}$ ZB, Yang CL, Zhang J, Zeng J. A protein fragment derived from DNA-topoisomerase I as a novel tumourassociated antigen for the detection of early stage carcinoma. British journal of cancer. 2016.
6. Recavarren-Arce S, Leon-Barua R, Cok J, Berendson R, Gilman RH, Ramirez-Ramos A, Rodriguez C, Spira WM. Helicobacter pylori and progressive gastric pathology that predisposes to gastric cancer. Scand J Gastroenterol Suppl. 1991; 181:51-57.

7. Correa P. Human gastric carcinogenesis: a multistep and multifactorial process--First American Cancer Society Award Lecture on Cancer Epidemiology and Prevention. Cancer research. 1992; 52:6735-6740.

8. Suzuki H, Oda I, Abe S, Sekiguchi M, Mori G, Nonaka S, Yoshinaga S, Saito Y. High rate of 5-year survival among patients with early gastric cancer undergoing curative endoscopic submucosal dissection. Gastric cancer. 2016; 19:198-205.

9. Kim DY, Hong SJ, Cho GS, Jeong GA, Kim HK, Han JP, Lee YN, Ko BM, Lee MS. Long-term efficacy of endoscopic submucosal dissection compared with surgery for early gastric cancer: a retrospective cohort study. Gut Liver. 2014; 8:519-525.

10. Tan YK, Fielding JW. Early diagnosis of early gastric cancer. Eur J Gastroenterol Hepatol. 2006; 18:821-829.

11. Tashiro A, Sano M, Kinameri K, Fujita K, Takeuchi Y. Comparing mass screening techniques for gastric cancer in Japan. World J Gastroenterol. 2006; 12:4873-4874.

12. Boeriu A, Boeriu C, Drasovean S, Pascarenco O, Mocan S, Stoian M, Dobru D. Narrow-band imaging with magnifying endoscopy for the evaluation of gastrointestinal lesions. World journal of gastrointestinal endoscopy. 2015; 7:110-120.

13. Kaise M. Advanced endoscopic imaging for early gastric cancer. Best Pract Res Clin Gastroenterol. 2015; 29:575-587.

14. Kaise M, Ohkura Y, lizuka T, Kimura R, Nomura K, Kuribayashi Y, Yamada A, Yamashita S, Furuhata T, Kikuchi D, Ogawa O, Matsui A, Mitani $T$, et al. Endocytoscopy is a promising modality with high diagnostic accuracy for gastric cancer. Endoscopy. 2015; 47:19-25.

15. Lee HL, Eun CS, Lee OY, Han DS, Yoon BC, Choi HS, Hahm JS, Koh DH. When do we miss synchronous gastric neoplasms with endoscopy? Gastrointest Endosc. 2010; 71:1159-1165.

16. Nomura K, Kaise M, Kikuchi D, Iizuka T, Fukuma Y, Kuribayashi Y, Tanaka M, Toba T, Furuhata T, Yamashita S, Matsui A, Mitani T, Hoteya S. Recognition Accuracy Using 3D Endoscopic Images for Superficial Gastrointestinal Cancer: A Crossover Study. Gastroenterol Res Pract. 2016; 2016:4561468.

17. Tie J, Zhang X, Fan D. Epigenetic roles in the malignant transformation of gastric mucosal cells. Cellular and molecular life sciences. 2016; 73:4599-4610.

18. Sapari NS, Loh M, Vaithilingam A, Soong R. Clinical potential of DNA methylation in gastric cancer: a metaanalysis. PLoS One. 2012; 7:e36275.

19. Kang GH, Lee S, Cho NY, Gandamihardja T, Long TI, Weisenberger DJ, Campan M, Laird PW. DNA methylation profiles of gastric carcinoma characterized by quantitative DNA methylation analysis. Lab Invest. 2008; 88:161-170. 
20. Nakamura J, Tanaka T, Kitajima Y, Noshiro H, Miyazaki K. Methylation-mediated gene silencing as biomarkers of gastric cancer: a review. World J Gastroenterol. 2014; 20:11991-12006.

21. Leung WK, To KF, Chu ES, Chan MW, Bai AH, Ng EK, Chan FK, Sung JJ. Potential diagnostic and prognostic values of detecting promoter hypermethylation in the serum of patients with gastric cancer. Br J Cancer. 2005; 92:2190-2194.

22. Oishi Y, Watanabe Y, Yoshida Y, Sato Y, Hiraishi T, Oikawa R, Maehata T, Suzuki H, Toyota M, Niwa H, Suzuki M, Itoh F. Hypermethylation of Sox17 gene is useful as a molecular diagnostic application in early gastric cancer. Tumour Biol. 2012; 33:383-393.

23. Watanabe Y, Kim HS, Castoro RJ, Chung W, Estecio MR, Kondo K, Guo Y, Ahmed SS, Toyota M, Itoh F, Suk KT, Cho MY, Shen L, et al. Sensitive and specific detection of early gastric cancer with DNA methylation analysis of gastric washes. Gastroenterology. 2009; 136:2149-2158.

24. Sepulveda JL, Gutierrez-Pajares JL, Luna A, Yao Y, Tobias JW, Thomas S, Woo Y, Giorgi F, Komissarova EV, Califano A, Wang TC, Sepulveda AR. High-definition $\mathrm{CpG}$ methylation of novel genes in gastric carcinogenesis identified by next-generation sequencing. Mod Pathol. 2016; 29:182-193.

25. Kaneda A, Tsukamoto T, Takamura-Enya T, Watanabe N, Kaminishi M, Sugimura T, Tatematsu M, Ushijima T. Frequent hypomethylation in multiple promoter $\mathrm{CpG}$ islands is associated with global hypomethylation, but not with frequent promoter hypermethylation. Cancer Sci. 2004; 95:58-64.

26. Lee JR, Chung WC, Kim JD, Lee KM, Paik CN, Jung SH, Jung JH, Lee YK, Han SW. Differential LINE1 Hypomethylation of Gastric Low-Grade Dysplasia from High Grade Dysplasia and Intramucosal Cancer. Gut Liver. 2011; 5:149-153.

27. Maeda M, Moro H, Ushijima T. Mechanisms for the induction of gastric cancer by Helicobacter pylori infection: aberrant DNA methylation pathway. Gastric Cancer. 2016.

28. Wu WK, Yu J, Chan MT, To KF, Cheng AS. Combinatorial epigenetic deregulation by Helicobacter pylori and EpsteinBarr virus infections in gastric tumourigenesis. J Pathol. 2016; 239:245-249.

29. Leodolter A, Alonso S, Gonzalez B, Ebert MP, Vieth M, Rocken C, Wex T, Peitz U, Malfertheiner P, Perucho M. Somatic DNA Hypomethylation in H. pylori-Associated High-Risk Gastritis and Gastric Cancer: Enhanced Somatic Hypomethylation Associates with Advanced Stage Cancer. Clinical and translational gastroenterology. 2015; 6:e85.

30. Zhang Y, Zhang XR, Park JL, Kim JH, Zhang L, Ma JL, Liu WD, Deng DJ, You WC, Kim YS, Pan KF. Genome-wide DNA methylation profiles altered by Helicobacter pylori in gastric mucosa and blood leukocyte DNA. Oncotarget. 2016; 7:37132-37144. doi: 10.18632/oncotarget.9469.

31. Kosumi K, Baba Y, Ishimoto T, Harada K, Miyake K, Izumi D, Tokunaga R, Murata A, Eto K, Sugihara H,
Shigaki H, Iwagami S, Sakamoto Y, et al. Relationship between LINE-1 hypomethylation and Helicobacter pylori infection in gastric mucosae. Medical oncology. 2015; 32:117.

32. Pepe MS, Etzioni R, Feng Z, Potter JD, Thompson ML, Thornquist M, Winget M, Yasui Y. Phases of biomarker development for early detection of cancer. J Natl Cancer Inst. 2001; 93:1054-1061.

33. Jaffe AE, Feinberg AP, Irizarry RA, Leek JT. Significance analysis and statistical dissection of variably methylated regions. Biostatistics. 2012; 13:166-178.

34. Jaffe AE, Murakami P, Lee H, Leek JT, Fallin MD, Feinberg AP, Irizarry RA. Bump hunting to identify differentially methylated regions in epigenetic epidemiology studies. Int J Epidemiol. 2012; 41:200-209.

35. Li D, Xie Z, Pape ML, Dye T. An evaluation of statistical methods for DNA methylation microarray data analysis. BMC Bioinformatics. 2015; 16:217.

36. Rhee YY, Kim KJ, Kang GH. CpG Island Methylator Phenotype-High Colorectal Cancers and Their Prognostic Implications and Relationships with the Serrated Neoplasia Pathway. Gut Liver. 2017; 11:38-46.

37. Tsygankov AY. TULA-family proteins: a new class of cellular regulators. J Cell Physiol. 2013; 228:43-49.

38. Kowanetz K, Crosetto N, Haglund K, Schmidt MH, Heldin CH, Dikic I. Suppressors of T-cell receptor signaling Sts- 1 and Sts-2 bind to $\mathrm{Cbl}$ and inhibit endocytosis of receptor tyrosine kinases. J Biol Chem. 2004; 279:32786-32795.

39. Feshchenko EA, Smirnova EV, Swaminathan G, Teckchandani AM, Agrawal R, Band H, Zhang X, Annan RS, Carr SA, Tsygankov AY. TULA: an SH3- and UBA-containing protein that binds to c-Cbl and ubiquitin. Oncogene. 2004; 23:4690-4706.

40. Holz C, Niehr F, Boyko M, Hristozova T, Distel L, Budach V, Tinhofer I. Epithelial-mesenchymal-transition induced by EGFR activation interferes with cell migration and response to irradiation and cetuximab in head and neck cancer cells. Radiother Oncol. 2011; 101:158-164.

41. Agrawal R, Carpino N, Tsygankov A. TULA proteins regulate activity of the protein tyrosine kinase Syk. J Cell Biochem. 2008; 104:953-964.

42. Luangdilok S, Box C, Patterson L, Court W, Harrington K, Pitkin L, Rhys-Evans P, P Oc, Eccles S. Syk tyrosine kinase is linked to cell motility and progression in squamous cell carcinomas of the head and neck. Cancer research. 2007; 67:7907-7916.

43. Chuang JY, Huang YL, Yen WL, Chiang IP, Tsai MH, Tang CH. Syk/JNK/AP-1 signaling pathway mediates interleukin-6-promoted cell migration in oral squamous cell carcinoma. Int J Mol Sci. 2014; 15:545-559.

44. Lee ST, Feng M, Wei Y, Li Z, Qiao Y, Guan P, Jiang X, Wong CH, Huynh K, Wang J, Li J, Karuturi KM, Tan EY, et al. Protein tyrosine phosphatase UBASH3B is overexpressed in triple-negative breast cancer and promotes 
invasion and metastasis. Proc Natl Acad Sci U S A. 2013; 110:11121-11126.

45. Nguyen H, Hiscott J, Pitha PM. The growing family of interferon regulatory factors. Cytokine Growth Factor Rev. 1997; 8:293-312.

46. Tanaka N, Taniguchi T. The interferon regulatory factors and oncogenesis. Semin Cancer Biol. 2000; 10:73-81.

47. Marecki S, Fenton MJ. The role of IRF-4 in transcriptional regulation. J Interferon Cytokine Res. 2002; 22:121-133.

48. Pernis AB. The role of IRF-4 in B, T cell activation and differentiation. J Interferon Cytokine Res. 2002; 22:111-120.

49. Jarzynka MJ, Hu B, Hui KM, Bar-Joseph I, Gu W, Hirose T, Haney LB, Ravichandran KS, Nishikawa R, Cheng SY. ELMO1 and Dock180, a bipartite Rac1 guanine nucleotide exchange factor, promote human glioma cell invasion. Cancer research. 2007; 67:7203-7211.

50. Yagi K, Akagi K, Hayashi H, Nagae G, Tsuji S, Isagawa T, Midorikawa Y, Nishimura Y, Sakamoto H, Seto Y, Aburatani H, Kaneda A. Three DNA methylation epigenotypes in human colorectal cancer. Clin Cancer Res. 2010; 16:21-33.

51. Smyth LJ, McKay GJ, Maxwell AP, McKnight AJ. DNA hypermethylation and DNA hypomethylation is present at different loci in chronic kidney disease. Epigenetics. 2014; 9:366-376.

52. Whitaker JW, Boyle DL, Bartok B, Ball ST, Gay S, Wang W, Firestein GS. Integrative omics analysis of rheumatoid arthritis identifies non-obvious therapeutic targets. PLoS One. 2015; 10:e0124254.

53. Massari ME, Rivera RR, Voland JR, Quong MW, Breit TM, van Dongen JJ, de Smit O, Murre C. Characterization of ABF-1, a novel basic helix-loop-helix transcription factor expressed in activated B lymphocytes. Mol Cell Biol. 1998; 18:3130-3139.

54. Robb L, Brodnicki T, Copeland NG, Gilbert DJ, Jenkins NA, Harvey RP. Assignment of the human helix-loop-helix transcription factor gene musculin/activated B-cell factor-1 (MSC) to chromosome 8q21 and its mouse homologue (Msc) to the proximal region of chromosome 1. Genomics. 1999; 57:318-319.

55. Moncaut N, Cross JW, Siligan C, Keith A, Taylor K, Rigby PW, Carvajal JJ. Musculin and TCF21 coordinate the maintenance of myogenic regulatory factor expression levels during mouse craniofacial development. Development. 2012; 139:958-967.

56. Laird PW, Jaenisch R. The role of DNA methylation in cancer genetic and epigenetics. Annu Rev Genet. 1996; 30:441-464.

57. Heyn H, Vidal E, Ferreira HJ, Vizoso M, Sayols S, Gomez A, Moran S, Boque-Sastre R, Guil S, MartinezCardus A, Lin CY, Royo R, Sanchez-Mut JV, et al. Epigenomic analysis detects aberrant super-enhancer DNA methylation in human cancer. Genome Biol. 2016; 17:11.

58. Heyn H, Sayols S, Moutinho C, Vidal E, Sanchez-Mut JV, Stefansson OA, Nadal E, Moran S, Eyfjord JE, Gonzalez-
Suarez E, Pujana MA, Esteller M. Linkage of DNA methylation quantitative trait loci to human cancer risk. Cell Rep. 2014; 7:331-338.

59. Esteller M. Aberrant DNA methylation as a cancer-inducing mechanism. Annu Rev Pharmacol Toxicol. 2005; 45:629-656.

60. Jair KW, Bachman KE, Suzuki H, Ting AH, Rhee I, Yen RW, Baylin SB, Schuebel KE. De novo CpG island methylation in human cancer cells. Cancer research. 2006; 66:682-692.

61. Toyota M, Ahuja N, Suzuki H, Itoh F, Ohe-Toyota M, Imai K, Baylin SB, Issa JP. Aberrant methylation in gastric cancer associated with the $\mathrm{CpG}$ island methylator phenotype. Cancer research. 1999; 59:5438-5442.

62. Enomoto S, Maekita T, Tsukamoto T, Nakajima T, Nakazawa K, Tatematsu M, Ichinose M, Ushijima T. Lack of association between $\mathrm{CpG}$ island methylator phenotype in human gastric cancers and methylation in their background non-cancerous gastric mucosae. Cancer Sci. 2007; 98:1853-1861.

63. Maekita T, Nakazawa K, Mihara M, Nakajima T, Yanaoka K, Iguchi M, Arii K, Kaneda A, Tsukamoto T, Tatematsu M, Tamura G, Saito D, Sugimura T, et al. High levels of aberrant DNA methylation in Helicobacter pylori-infected gastric mucosae and its possible association with gastric cancer risk. Clin Cancer Res. 2006; 12:989-995.

64. Matsusaka K, Funata S, Fukayama M, Kaneda A. DNA methylation in gastric cancer, related to Helicobacter pylori and Epstein-Barr virus. World J Gastroenterol. 2014; 20:3916-3926.

65. da Costa DM, Neves-Filho EH, Alves MK, Rabenhorst SH. Interleukin polymorphisms and differential methylation status in gastric cancer: an association with Helicobacter pylori infection. Epigenomics. 2013; 5:167-175.

66. Alves MK, Ferrasi AC, Lima VP, Ferreira MV, de Moura Campos Pardini MI, Rabenhorst SH. Inactivation of COX-2, HMLH1 and CDKN2A gene by promoter methylation in gastric cancer: relationship with histological subtype, tumor location and Helicobacter pylori genotype. Pathobiology. 2011; 78:266-276.

67. Yu D, Cao T, Han YD, Huang FS. Relationships between MGMT promoter methylation and gastric cancer: a metaanalysis. Onco Targets Ther. 2016; 9:6049-6057.

68. Wu L, Zhang C, Wang X, Ding X, Deng J, Liang H. Methylation of ASC/TMS1 promoter is associated with poor prognosis of patients with gastric cancer. Clin Transl Oncol. 2016; 18:296-303.

69. Boyacioglu SO, Kasap E, Yuceyar H, Korkmaz M. Alteration in Methylation Pattern of Retinoblastoma 1 Gene Promotor Region in Intestinal Metaplasia with or without Helicobacter pylori and Gastric Cancer Patients. Adv Clin Exp Med. 2016; 25:465-470.

70. Han F, Sun LP, Liu S, Xu Q, Liang QY, Zhang Z, Cao HC, Yu J, Fan DM, Nie YZ, Wu KC, Yuan Y. Promoter methylation of RNF180 is associated with H.pylori infection and serves as a marker for gastric cancer and atrophic gastritis. Oncotarget. 2016; 7:24800-24809. doi: 10.18632/oncotarget.8523. 
71. Zhang X, Zhang X, Sun B, Lu H, Wang D, Yuan X, Huang Z. Detection of aberrant promoter methylation of RNF180, DAPK1 and SFRP2 in plasma DNA of patients with gastric cancer. Oncol Lett. 2014; 8:1745-1750.

72. Moghbeli M, Moaven O, Memar B, Raziei HR, Aarabi A, Dadkhah E, Forghanifard MM, Manzari F, Abbaszadegan MR. Role of hMLH1 and E-cadherin promoter methylation in gastric cancer progression. J Gastrointest Cancer. 2014; 45:40-47.

73. Kim JJ, Chung SW, Kim JH, Kim JW, Oh JS, Kim S, Song SY, Park J, Kim DH. Promoter methylation of helicase-like transcription factor is associated with the early stages of gastric cancer with family history. Ann Oncol. 2006; 17:657-662.

74. Bernal C, Aguayo F, Villarroel C, Vargas M, Diaz I, Ossandon FJ, Santibanez E, Palma M, Aravena E, Barrientos C, Corvalan AH. Reprimo as a potential biomarker for early detection in gastric cancer. Clin Cancer Res. 2008; 14:6264-6269.

75. Saavedra K, Valbuena J, Olivares W, Marchant MJ, Rodriguez A, Torres-Estay V, Carrasco-Avino G, Guzman L, Aguayo F, Roa JC, Corvalan AH. Loss of Expression of Reprimo, a p53-induced Cell Cycle Arrest Gene, Correlates with Invasive Stage of Tumor Progression and p73 Expression in Gastric Cancer. PLoS One. 2015; 10:e0125834.

76. Shin CM, Kim N, Jung Y, Park JH, Kang GH, Park WY, Kim JS, Jung HC, Song IS. Genome-wide DNA methylation profiles in noncancerous gastric mucosae with regard to Helicobacter pylori infection and the presence of gastric cancer. Helicobacter. 2011; 16:179-188.

77. Chong Y, Mia-Jan K, Ryu H, Abdul-Ghafar J, Munkhdelger J, Lkhagvadorj S, Jung SY, Lee M, Ji SY, Choi E, Cho MY. DNA methylation status of a distinctively different subset of genes is associated with each histologic Lauren classification subtype in early gastric carcinogenesis. Oncol Rep. 2014; 31:2535-2544.

78. Yamamoto E, Toyota M, Suzuki H, Kondo Y, Sanomura T, Murayama Y, Ohe-Toyota M, Maruyama R, Nojima M, Ashida M, Fujii K, Sasaki Y, Hayashi N, et al. LINE-1 hypomethylation is associated with increased $\mathrm{CpG}$ island methylation in Helicobacter pylori-related enlargedfold gastritis. Cancer Epidemiol Biomarkers Prev. 2008; 17:2555-2564.

79. Cravo M, Pinto R, Fidalgo P, Chaves P, Gloria L, NobreLeitao C, Costa Mira F. Global DNA hypomethylation occurs in the early stages of intestinal type gastric carcinoma. Gut. 1996; 39:434-438.

80. Al-Awadhi H, John R, Al-Marzooqi F, Vincze A, Branicki F, Karam SM. Sequential alterations in gastric biopsies and tumor tissues support the multistep process of carcinogenesis. Histology and histopathology. 2011; 26:1153-1164.

81. Smith ML, Baggerly KA, Bengtsson H, Ritchie ME, Hansen KD. illuminaio: An open source IDAT parsing tool for Illumina microarrays. F1000Research. 2013; 2:264.

82. Triche TJ Jr, Weisenberger DJ, Van Den Berg D, Laird PW, Siegmund KD. Low-level processing of Illumina Infinium DNA Methylation BeadArrays. Nucleic acids research. 2013; 41:e90.

83. Aryee MJ, Jaffe AE, Corrada-Bravo H, Ladd-Acosta C, Feinberg AP, Hansen KD, Irizarry RA. Minfi: a flexible and comprehensive Bioconductor package for the analysis of Infinium DNA methylation microarrays. Bioinformatics. 2014.

84. Hoque MO, Begum S, Topaloglu O, Chatterjee A, Rosenbaum E, Van Criekinge W, Westra WH, Schoenberg M, Zahurak M, Goodman SN, Sidransky D. Quantitation of promoter methylation of multiple genes in urine DNA and bladder cancer detection. J Natl Cancer Inst. 2006; 98:996-1004.

85. Tyner C, Barber GP, Casper J, Clawson H, Diekhans M, Eisenhart C, Fischer CM, Gibson D, Gonzalez JN, Guruvadoo L, Haeussler M, Heitner S, Hinrichs AS, et al. The UCSC Genome Browser database: 2017 update. Nucleic Acids Res. 2017; 45:D626-D634.

86. Li LC, Dahiya R. MethPrimer: designing primers for methylation PCRs. Bioinformatics. 2002; 18:1427-1431. 